\title{
Biblioteca na vida acadêmica de um estudante surdo: um relato de experiência
}

\author{
The library in the academic life of a deaf student: an experience report \\ Danielle da Silva Pinheiro Wellichan \\ Doutoranda em Educação pela Universidade Estadual Paulista - UNESP, campus de Marília, Brasil. \\ https://orcid.org/0000-0002-6978-7361 \\ E-mail: danysp@gmail.com \\ Carla C. Tescaro Santos Lino \\ Doutoranda em Educação pela Universidade Estadual Paulista - UNESP, campus de Marília, Brasil. \\ https://orcid.org/0000-0002-4339-7832 \\ E-mail: carlatescaro@yahoo.com.br
}

Eduardo José Manzini Doutor em Psicologia pelo Instituto de Psicologia da Universidade de São Paulo - USP, Brasil. Docente do Programa de Pós-Graduação em Educação da Universidade Estadual Paulista - UNESP, campus de

Marília, Brasil.

https://orcid.org/0000-0002-7157-8227

E-mail: eduardo.manzini@unesp.br

\section{Resumo}

Ao ingressar na universidade, o estudante com deficiência auditiva ou surdez depara-se com uma realidade que nem sempre é a mesma que vivenciou em escolas bilíngues até o Ensino Médio. Por ser um universo maior e mais diversificado, nem sempre está presente um profissional intérprete de Libras/Língua portuguesa, de materiais bilíngues, e a comunicação pode não acontecer de forma acessível à sua compreensão. Essa ruptura na realidade acadêmica desse estudante é mais frequente do que se imagina e pode apresentar fatores que comprometem sua trajetória de estudos e aprendizagens. A literatura mostra que existem possibilidades para estabelecer uma relação satisfatória entre biblioteca - estudante com deficiência auditiva ou surdo - bibliotecário, mas como ela acontece? O que pode ser oferecido para um estudante com essas condições como usuário de uma biblioteca universitária? Como ocorrer o atendimento para esse estudante? Para tentar responder a essas perguntas e conhecer essa relação, buscaram-se subsídios teóricos na literatura nacional para construir o referencial deste estudo, que objetivou analisar as respostas a uma entrevista realizada com um estudante surdo, matriculado em um programa de pósgraduação, sobre sua relação com a biblioteca (equipe e ambiente). Os resultados apontam desafios a serem superados pelos usuários com deficiência, nas bibliotecas, como a falta de comunicação, ausência de acervo e recursos especializados. Conclui-se, portanto, que os atendimentos inclusivos para o usuário com deficiência auditiva ou surdez ainda não acontecem como deveriam e que as bibliotecas precisam estar atentas ao cumprimento de sua responsabilidade na sociedade inclusiva.

Palavras-chave: Deficiência auditiva. Surdez. Bibliotecas. Ensino Superior. Acessibilidade.

\begin{abstract}
When deaf students get enrolled in a university they are faced with a reality that is not always the same as that experienced in bilingual schools until high school. As it is a wider and more diverse universe, there may not be the presence of the professional interpreter of Libras / Portuguese language, bilingual materials and communication may not happen in an accessible way for their understanding. This rupture in the academic reality of the deaf student is more frequent than it is thought and may present factors that compromise their trajectory of studies and learning. The literature shows us that there are possibilities to establish a satisfactory relationship between library - deaf student - librarian, but how does it happen? What can be offered to a deaf student using a university library? How does the care for this student occur? In order to try to answer these questions and get to know this relationship, theoretical support was sought in the national literature to build the framework of this study that aimed to analyze the responses to an interview conducted with a deaf student enrolled in a postgraduate program about his relationship with the library (staff and environment). The results point to challenges to be overcome by users with disabilities in libraries, such as the lack of communication, the absence of collections and specialized resources. It is concluded, therefore, that inclusive care for the deaf user still does not happen as it should and that libraries need to pay attention to fulfill their responsibility in the inclusive society.
\end{abstract}

Keywords: Deafness. Libraries. University Education. Accessibility.

InCID: R. Ci. Inf. e Doc., Ribeirão Preto, v. 12, n. 2, p. 284-304, set. 2021./fev. 2022.

DOI: 10.11606/issn.2178-2075.v12i2p284-304 


\section{Introdução}

A surdez, congênita ou adquirida, impõe ao surdo dificuldades no convívio social. Para a pessoa surda, a menos que haja outras deficiências associadas, a falta de comunicação é a grande barreira a ser enfrentada. A própria história dessa parcela surda da humanidade remete a fatos que incluem negações daqueles que se apresentam diferentes do padrão estabelecido pela sociedade/comunidade em que vivem como "normal" e que, diante disso, são excluídos de sistemas educacionais, sociais e culturais. Por isso e com isso, buscam conquistar um espaço na sociedade que também lhes pertence.

As dificuldades causadas pela surdez, também considerada uma "deficiência invisível" por causa da não identificação pela observação imediata, podem dificultar, à primeira vista, o estabelecimento de relações da comunidade ouvinte com os surdos (FERREIRA; CHAGAS, 2016). Dados estatísticos oficiais apontam que o Brasil possui 5,1\% de pessoas com deficiência auditiva, entre surdez e dificuldades para ouvir (IBGE, 2010).

É preciso esclarecer a distinção existente entre a deficiência auditiva e a surdez, pois, não se trata da mesma situação. Conforme Honora e Frizanco (2015) descreveram, o indivíduo com deficiência auditiva, embora possa se comunicar pela fala, possui alterações (lesões) na estrutura da orelha ou na composição do aparelho auditivo, ocasionadas pela diminuição leve ou moderada da capacidade de perceber o som. Com a surdez, embora também seja caracterizada pelas alterações nas estruturas, apresenta uma perda mais profunda, e geralmente, a comunicação acontece por meio da Língua Brasileira de Sinais (Libras).

Com o avanço dos movimentos internacionais de integração e de inclusão escolar, a partir da década de 1990, as pessoas com deficiência começaram a alcançar um pouco mais de atenção nas políticas educacionais em vários países. Assim, diretrizes advindas da Educação Especial para a Educação Básica no Brasil passaram a contemplar as questões relativas ao estudante com deficiência no sistema regular de ensino (BRASIL, 1996) e, dessa forma, as matrículas das pessoas com deficiência começaram a surgir nas escolas regulares de ensino.

Mediante leis e decretos, o direito à educação de todos está estabelecido pela Constituição Federal (BRASIL, 1988): é dever do estado e da família. Independentemente da deficiência da pessoa/do estudante, o direito aos estudos está previsto em lei e cabe à sociedade buscar estratégias e mecanismos que possibilitem o acesso e a acessibilidade para essas pessoas. 
Conforme o texto da Lei n.13.146/2015, a acessibilidade refere-se à

[...] possibilidade e condição de alcance para utilização, com segurança e autonomia, de espaços, mobiliários, equipamentos urbanos, edificações, transportes, informação e comunicação, inclusive seus sistemas e tecnologias, bem como de outros serviços e instalações abertos ao público, de uso público ou privados de uso coletivo, tanto na zona urbana como na rural, por pessoa com deficiência ou com mobilidade reduzida (BRASIL, 2015, n.p.)

Para o surdo, a acessibilidade está além da estrutura, é parte de um contexto que pode facilitar as suas condições no ambiente, pois ele "[...] pertence a um mundo de experiência visual e não auditiva" (PERLIN, 2013, p. 56).

\begin{abstract}
Qualquer adaptação que ajude o elemento visual de comunicação irá beneficiar pessoas surdas (eixo arquitetônico). Uma iluminação que clareia o rosto é essencial para os leitores labiais que dependem em grande parte da leitura do rosto para entender as formações das diferentes palavras. Uma sinalização eficaz beneficia também aqueles surdos que não estão confortáveis em pedir ajuda de ouvintes. Um ambiente com uma boa acústica pode fazer toda a diferença para uma pessoa com deficiência de audição, móveis que absorvem o ruído (como tapetes e cortinas) fazem um ambiente mais utilizável acusticamente (MIGLIONI; SANTOS, 2017, p. 145).
\end{abstract}

De acordo com a Associação Brasileira de Normas Técnicas (ABNT), as normas NBR 15599/2008 e 9050/2015, a sinalização nos ambientes deve ser explicativa, clara e seguir uma sequência lógica de orientação e passível de repetição quando houver alteração de direção. Deve estar visível, de forma que possa ser lida por pessoas sentadas, em pé ou em movimento, em placas que respeitem ângulos de alcance visual. O uso do símbolo internacional de surdez deve ser utilizado "[...] em todos os locais que se destinem equipamentos, produtos, procedimentos ou serviços para pessoas com deficiência auditiva [...]" (ABNT, 2015, p.41). A informação visual, portanto,

[...] deve ser legível e seguir padrões que permitam a visualização e entendimento da sinalização, padrões estes relacionados no item 5 da norma referentes ao contraste (cores do texto e fundo), iluminação do ambiente, estilo de redação, tamanho da fonte, distância entre outras especificações (MIRANDA, 2017, p. 2)

A presença de intérpretes de Libras também deve ser indicada por símbolos internacionais, bem como a presença de telefones com teclado (ABNT, 2008; FORTALECIMENTO, 2016). No entanto, é preciso acompanhamento e atualização no uso de tais recursos, pois os telefones com teclado, na atualidade, possuem pouco uso entre os surdos, e os aplicativos que apresentam acessibilidade em vídeos nem sempre possuem avatar com expressão suficiente para entendimento. Antes de oferecer, é preciso analisar o que de fato pode ser disponibilizado, caso contrário não haverá procura. 
A acessibilidade para o surdo também inclui a Língua Brasileira de Sinais (Libras) considerada uma peça fundamental em um processo de inclusão, pois atende às necessidades comunicacionais ao captar as experiências visuais e expressá-las por meio de sinais (STROBEL, 2008).

De acordo com a legislação brasileira - Lei n.10.436, de 24 de abril de 2002 - a Libras foi legalizada entre as comunidades surdas e alcançou o status de língua. Esta lei determina também aos órgãos públicos e instituições de ensino a obrigatoriedade de gerenciar recursos para atendê-los. O Decreto $n^{\circ}$ 5.626/2005 regulamenta a inclusão nessas condições e estabelece estratégias a serem trabalhadas no Atendimento Educacional Especializado (AEE), como previsto no Art. 208 da Constituição Federal em parceria com o sistema público de ensino.

A partir do decreto, ficou estabelecido que as escolas proverão o ensino, o uso da Libras e oferecimento do tradutor e intérprete de Libras/Língua Portuguesa, além de professor para o ensino da Língua Portuguesa e regente de classe. Essas condições garantem o atendimento adequado às necessidades do estudante surdo, desde a Educação Infantil, em salas regulares, até o atendimento de apoio pedagógico à escolarização em salas de recursos em horário contraturno ao período da escolarização (BRASIL, 2002; 2005).

O AEE, as escolas bilíngues e os institutos especializados contribuem para a vida escolar das pessoas com deficiências, desde a Educação Infantil ao Ensino Médio; mas, no Ensino Superior, o estudante adentra uma nova realidade, que nem sempre o acolhe como deveria. A partir desse momento, o acesso, a permanência, a exclusão, a evasão e o abandono tornam-se fatores que precisam ser analisados e diminuídos para que os princípios de inclusão sejam cumpridos.

Com o uso e implementação em ambiente escolar, a Libras tornou-se disciplina curricular obrigatória oferecida nas licenciaturas em Pedagogia, Fonoaudiologia e demais cursos de licenciatura relacionados à Educação Básica, ao Ensino Fundamental I e II e ao Ensino Médio, com o objetivo de formar graduandos em uma perspectiva inclusiva (BRASIL, 2005).

A escolha da Libras como língua de instrução (L1) e do português (L2) pode fortalecer a capacidade cognitiva do indivíduo surdo no ensino que contempla a metodologia bilíngue, 
[...] temos duas estratégias principais; em uma, usamos uma língua para ensinar sobre uma outra língua; em outra, usamos uma língua para ensinar informações/conteúdo. Precisamos separar o aprendizado de conteúdo do aprendizado da língua. Ao usarmos uma língua para aprender uma segunda, uma vez que a segunda língua é aprendida e operante, temos agora a escolha de como acessar as informações/conteúdo. Podemos usar a primeira para acessar as informações/conteúdo ou podemos usar a segunda língua para acessar essas informações. Quando o acesso às informações se torna impedido, como quando as informações na segunda língua se tornam muito complexas ou além do nosso alcance, podemos nos voltar para a primeira língua para poder compreender. Isso então permitirá que o usuário da primeira língua analise como a segunda língua funciona para transmitir informações que seja simples e complexas. (SKLIAR, 1999, p. 121).

Pretende-se que familiares utilizem ambas as línguas para estimular os filhos surdos a se tornarem bilíngues desde cedo, para que tenham conhecimentos sobre o mundo. Porém, Skliar (1999) posiciona-se em defesa do bilinguismo como única proposta aceitável à educação de estudantes surdos, de forma a dar visibilidade e legitimidade à educação dessa parcela da população, baseado em um modelo socioantropológico, pois “[...] o surdo não precisa almejar uma vida semelhante ao ouvinte, podendo assumir sua surdez." (GOLDFELD, 1997, p. 38).

O fato é que, após uma década de sua implementação, as políticas educacionais inclusivas exigem um momento de avaliação (MANZINI; GERMANO; OLIVEIRA, 2018), pois professores e estudantes ainda enfrentam dificuldades de diversas naturezas para cumprir o que está previsto em lei, o que se encontra na prática.

E se a educação de surdos exige novas posturas dos profissionais e do próprio sistema educacional desde a Educação Infantil, ao longo da vida escolar não se torna mais fácil, mesmo sendo um direito previsto em lei, pois a cada etapa um desafio é apresentado para aqueles que se apresentam de alguma forma diferente dos demais.

Assim, o termo Educação Inclusiva surge como um processo "[...] fundamentado na concepção de direitos humanos, que conjuga igualdade e diferença como valores indissociáveis, e que avança em relação à ideia de equidade formal” (BRASIL, 2008, n.p), que amplia as possibilidades de participação de um estudante com deficiência em uma educação que está além da garantia de vaga em determinada fase escolar. Trata-se de um cenário que precisa ser transformado para que todos possam usufruir do ambiente e das condições em sua totalidade.

A capacitação de professores em Libras e a presença de tradutor e/ou intérprete de Libras são exigências para o estudante surdo em escolas e universidades, mas não garante sua inclusão na sociedade. Ou seja, legislações foram desenvolvidas, ampliações para o conhecimento sobre a língua foram estendidas para algumas profissões, porém, a inclusão do surdo, assim como 
acontece em outras deficiências, está longe de ser efetiva, mesmo que bons resultados já tenham sido alcançados.

Por parte das autoridades, verificam-se muitos discursos políticos e poucas ações no sentido em se fazer cumprir com os ordenamentos jurídicos, dispositivos legais e normativos, os quais apoiam e defendem a todos o direito de igualdade, de ir e vir, de acessibilidade, de educação, assim como em relação a tantos outros direitos previstos em tais documentos (SILVA, 2010, p. 182)

Para que uma instituição de ensino superior seja considerada inclusiva, é preciso mais do que mudanças na infraestrutura, é necessário “[...] envolver o respeito pelas diferenças e pela diversidade, incluindo mudanças de postura profissional e consequentemente de toda comunidade local como colaboradores, corpo docente e discente" (WELLICHAN; SOUZA, 2017, p. 150), pois, como citado por Heringer (2018, p. 12),

[...] o sucesso efetivo das políticas de inclusão na educação superior vai se dar plenamente na medida em que sejam garantidas as condições de igualdade de oportunidades para os estudantes de diferentes origens sociais e características socioeconômicas na sua vivência, integração, percepção, apropriação e afiliação ao ambiente universitário. Tais condições, a nosso ver, são geradas por um conjunto de medidas de ordem institucional e também por disposições dos atores envolvidos, principalmente gestores, docentes, funcionários e colegas que possibilitem a efetiva inserção destes estudantes na vida universitária.

Pensando em um estudante com deficiência que chega à universidade, é preciso pensar no universo que envolve a fase que se inicia no processo seletivo. Para um estudante com deficiência, não se deve seguir a padronização do desempenho para candidatos sem deficiência, uma vez que aquele exigirá procedimentos especiais, como a disponibilização de materiais ou mobiliários específicos para a realização da prova e diferenciação no tempo de duração (BATISTA; NASCIMENTO, 2018).

Passado o processo seletivo, a universidade precisa garantir que esse estudante, se aprovado, tenha condições de se manter naquele ambiente. Para isso, todos os momentos desde o ato da matrícula, o planejamento e as estratégias de aprendizado, a convivência em sala de aula, o uso de laboratórios, refeitórios e os atendimentos em diversos setores, inclusive na biblioteca - precisam ser planejados e adequados de acordo com as necessidades dos estudantes com deficiência.

E é sobre este ponto que o texto a seguir foi desenvolvido, buscando respostas às seguintes questões: as pessoas com deficiência enfrentam desafios quando se trata de acessar bibliotecas e usar seus recursos? O que pode ser oferecido em termos de produtos e serviços 
para um usuário da informação surdo? Como deve ser o atendimento? O que o bibliotecário precisa realizar para que possa proporcionar um ambiente inclusivo para o usuário surdo?

Com o objetivo de conhecer a percepção de um estudante surdo sobre a biblioteca e seu atendimento em um ambiente universitário, propôs-se a realizar uma entrevista com um estudante surdo, matriculado em um programa de pós-graduação stricto sensu de uma instituição de Ensino Superior no estado de São Paulo, e conhecer, por meio dele, o que a biblioteca oferece para sua deficiência ${ }^{1}$ e como é sua relação com os profissionais do local.

\section{Biblioteca para um estudante surdo}

A democratização do ensino superior trouxe novas demandas para o ambiente universitário. No Brasil, com o crescimento da Educação Especial, surgiram oportunidades para divulgação e geração de conhecimentos a respeito da deficiência, assim como o desenvolvimento de uma rede de cooperação e apoio na formação de profissionais para orientar e auxiliar outros setores, além do sistema educacional existente, com a finalidade de ser reformulado diante das necessidades de um estudante com deficiência.

A nova demanda exigiu reformas, adaptações, reformulações e capacitações para que o estudante com deficiência pudesse usufruir do ambiente universitário como qualquer outro. Foi nesse contexto que as bibliotecas passaram por grandes transformações, desde aspectos estruturais, além da inserção de recursos de Tecnologia Assistiva, a criação de acervos com materiais adaptados e necessidade de capacitações para atender as pessoas com deficiência.

Essas transformações vieram como uma reafirmação de uma preocupação discutida, desde a década de 1970, na Biblioteconomia, sobre as mudanças de paradigmas, cuja ênfase estava nas técnicas, processos e nos sistemas que envolvem a informação e não no usuário. Percebe-se, desde então, que pensar no usuário, como um ponto de partida para as práticas bibliotecárias, não se trata de um assunto recente para a Biblioteconomia, embora ainda não caminhe como deveria (CAPURRO, 2003; SILVA, 2010; SILVA, 2012; DUARTE, 2012).

1 Alguns pesquisadores da área, como Skliar (1997), Lacerda (2000), Strobel (2008), entre outros, consideram o surdo não como uma pessoa com deficiência, mas como um sujeito subjetivo por utilizar uma língua de sinais para se comunicar/ para o estudante surdo / para sua especificidade de Ser Surdo. Porém, neste texto, ele será identificado como uma pessoa com deficiência por apresentar a perda auditiva no ambiente de bibliotecas. 
A falta de recursos atualizados ou de materiais especializados, as dificuldades na estrutura, nos processos e/ou na comunicação, e a falta de orientação no atendimento são algumas das dificuldades que a literatura apresenta sobre o usuário surdo, em bibliotecas. E diante dessa constatação, para participar dos movimentos de inclusão de forma ativa, as bibliotecas buscaram apoio em normas nacionais e padrões internacionais de acessibilidade para modificar, adequar suas estruturas e ampliar as possibilidades para as pessoas com deficiência, o que despertou a necessidade de novas habilidades e competências para o profissional e sua equipe (VIEIRA, 2014; FERREIRA; CHAGAS, 2016; SANTOS; DINIZ; RANGNI, 2017).

Com base nas diretrizes da American Library Association, as bibliotecas podem ser locais acolhedores para as pessoas com deficiência desde que ofereçam um "ambiente benéfico" com materiais, recursos e equipamentos, com incentivo e criação de novas experiências por meio de interações amigáveis. O documento sugere uma assistência ao usuário, que pode indicar como ser ajudado. Para isso, é preciso permitir que ele esclareça suas necessidades e que esteja ciente dos serviços oferecidos (ISHIMOTO; ROMÃO, 2015; MIRANDA 2015; ALA, 2017; MIGLIONI; SANTOS, 2017).

As diretrizes para serviços de bibliotecas, elaboradas pela International Federation of Library Associations and Institutions (IFLA, 2000), constituem um documento norteador para ações na biblioteca. Segundo essas diretrizes para os surdos, a falha na comunicação, a ausência de materiais didáticos e de representação cultural, a inexistência de parâmetros que viabilizem serviços voltados à categoria de usuários surdos compromete sua realidade. Por isso tais recursos não podem ser negados aos profissionais e aos usuários, para que fatores, como os citados anteriormente, não se tornem barreiras para os usuários da biblioteca.

Para o atendimento presencial em bibliotecas, a Associação Brasileira de Normas Técnicas recomenda:

[...] devem dispor de pelo menos um atendente com articulação orofacial que permita a leitura labial e quando houver atendimento com intérprete de Libras, o local deve estar sinalizado com símbolo internacional da surdez (ABNT, 2008, p. 6).

Essas informações devem ser divulgadas com a indicação de dias e horários do atendimento. Porém, para que a articulação orofacial possa acontecer, é preciso lembrar que nem todo surdo está apto à leitura labial, e alguns fatores - lábios leporinos, bigodes ou lábios muito finos - também podem dificultar essa leitura. Para complementar a adoção da norma, 
Miranda (2017) sugere que projetos de comunicação visual sejam elaborados para atender os usuários surdos, permitindo que utilizem a biblioteca com autonomia.

Com o crescente uso de dispositivos móveis e os recursos de Tecnologia Assistiva (TA) disponibilizados nas bibliotecas, alguns programas e aplicativos podem até ser "adotados" e utilizados na comunicação com o surdo, além de formas mais rápidas e instantâneas que utilizam redes sociais e e-mails, comprovadas como uma maneira de comunicação efetiva entre ouvintes e surdos (IFLA, 2000).

Sobre os recursos de TA para surdos, que podem ser disponibilizadas em bibliotecas, Ferreira e Chagas (2016, p. 92) citam: dicionários bilíngues (Português/Libras Libras/Português) ou ilustrados; sistemas de escrita da Libras como o SignWriting; editores como Signed e o Signsim, que fazem a tradução da Libras para a língua Portuguesa; o sistema Falibras, “[...] que capta a fala no microfone, o computador interpreta em Libras, na forma gestual, animada". Há, ainda, recursos aparentemente mais simples, mas com grande potencial de comunicação, como desenhos, ilustrações, slides, filmes entre outros materiais, que são necessários e podem atender os estudantes surdos. Embora nenhum deles exclua a necessidade da Libras na comunicação, os recursos tornam-se opções para que o atendimento em bibliotecas não seja negado ao usuário surdo.

Dias e Bom (2019) também citam a importância de tecnologias específicas, como: o software Vlibras (que possui ferramentas para a tradução de conteúdos de sites, áudio e textos para a Libras); a Wikilibras (sistema de correção e inclusão de novos sinais); o Hand Talk (aplicativo que transforma imagens e textos em Libras). Porém, usuários apontam que a falta de expressão do avatar e da sinalização, que não são tão claras, ainda apresentam dificuldades para a compreensão da pessoa surda, a considerar que a Libras é uma língua e não emaranhado de gestos aleatórios.

Torna-se ilusório acreditar que basta possuir recursos da Tecnologia Assistiva e organizar um ambiente fisicamente acessível, de acordo com recomendações de normas atuais, sem pensar na importância da capacitação de bibliotecários e equipes para interagir com o usuário surdo. Percebe-se, assim, que os recursos de TA nas bibliotecas podem ser variados em funcionalidades, custos e benefícios, não são tão desconhecidos e estão presentes em algumas realidades. Porém, faltam relatos de produtos e serviços criados a partir desses conhecimentos, o que desperta a hipótese de que tais recursos não sejam utilizados em sua integralidade, ou a divulgação de práticas inclusivas não estejam acontecendo. 
Investir em capacitação para o bibliotecário e equipe, por métodos variados, como cursos de atualizações, leituras, parcerias com profissionais especializados em deficiência, surdez e inclusão, e, principalmente, o contato com outras pessoas surdas, poderia possibilitar a compreensão do universo da cultura surda e as necessidades do usuário surdo (VIEIRA, 2014; FERREIRA; CHAGAS, 2016; MIRANDA, 2017; SANTOS; DINIZ; RAGNI, 2017; MIGLIOLI; SANTOS, 2017; DIAS; BOM, 2019).

Fruto de uma iniciativa estabelecida em parceria com a Biblioteca da Escola de Engenharia de São Carlos, a Comissão de Cultura e Extensão e a prefeitura do campus, foi oferecido um curso sobre os princípios básicos da Libras, para colaboradores da biblioteca, com duração de quatro meses. Segundo relato publicado, os participantes do curso não foram exclusivos da equipe da biblioteca, mas estudantes interessados e colaboradores de outros setores. Formou-se lista de espera e gerou produtos aproveitados pela própria biblioteca, como melhorias nas placas de sinalização e mapeamento de salas, além de orientações sobre acessos ao acervo, aos recursos e aos serviços disponíveis (ARAÚJO et al., 2017).

Um diagnóstico da biblioteca realizado em 2015, para a produção de uma dissertação, resultou em ações práticas para um sistema de bibliotecas de uma universidade no Rio de Janeiro. Foram implementados investimentos na área da Comunicação Visual em estantes, corredores e terminais de consulta, melhorias em relação ao site da biblioteca, oferecimento de treinamentos, criação de mapas de localização e visitas virtuais. Com os recursos de TA, foram adquiridos scanners de atendimento, de voz e planetário. Os autores relataram, no momento do estudo, que o sistema de bibliotecas não possuía intérpretes de Libras no atendimento, mas dispunha de uma bibliotecária que se comunicava na língua de sinais, “[...] o que contribui com a acessibilidade atitudinal, humanizando o atendimento [...]" (MIRANDA; COSTA; SILVA, 2017, p. 2016).

Conhecer a realidade de práticas inclusivas em bibliotecas é fundamental para fomentar a discussão a respeito da inclusão das pessoas com deficiência e/ou com limitações nos ambientes informacionais, e, como visto e recomendado em documentos norteadores para bibliotecas, deve-se ouvir o usuário para buscar uma aproximação com o profissional. Dessa forma, foi realizada uma entrevista com um usuário surdo, matriculado em um programa de pós-graduação, que descreveu sua percepção sobre a biblioteca, a equipe e sua convivência (ou ausência dela) nesse ambiente. 


\section{Método}

Para o referencial teórico deste estudo, buscaram-se em bases de dados nacionais estudos relativos à presença e ao atendimento de pessoas surdas em bibliotecas. Posteriormente, com a finalidade de descrever um contexto real, propôs-se a realização de uma entrevista com um estudante surdo (perda auditiva profunda), para que, associado à literatura existente, fosse possível descrever a realidade encontrada na universidade.

\section{Participante}

Participou de entrevista um jovem surdo, do gênero masculino, com 26 anos, solteiro, estudante de mestrado em um programa de pós-graduação de uma universidade no estado de São Paulo. Ele possuía duas graduações (uma na área de exatas e outra em ciências humanas) e, no momento da coleta, era professor em uma universidade pública. Trata-se de um estudante sinalizante em Libras, que conseguia ler a posição dos lábios pela leitura labial, cuja surdez profunda, causada pela meningite viral, foi diagnosticada aos dois anos de idade.

Em sua história, o participante foi matriculado em escola de surdos bilíngue (caracterizada como escola estadual com característica especial) onde aprendeu a Libras, seu meio de comunicação social, porém, oralizava com a família, cujos pais não eram proficientes em Libras, mas seu irmão mais novo era intérprete na língua. Na escola de surdos, estudou da Educação Infantil ao Ensino Médio.

\section{Procedimentos para coleta de dados e análise dos dados}

Para a entrevista, foi elaborado um roteiro semiestruturado (MANZINI, 2020) que passou por três versões e dois juízes, até a versão final. Após o convite formalizado e o esclarecimento ao participante a respeito do estudo, foram definidos a data e horário da entrevista.

A entrevista ${ }^{2}$ foi realizada via Google Meet, durante duas horas e meia, e a comunicação se deu em Língua Brasileira de Sinais (Libras). A entrevista foi gravada na plataforma em 
virtude da necessidade de transcrição da Libras para a Língua Portuguesa escrita, que ocorreu posteriormente. Uma das autoras é proficiente em Libras e, como houve alguns "travamentos" na plataforma durante a gravação, foi necessária atenção maior durante a transcrição da Libras para a língua portuguesa, que durou em torno de cinco horas. As respostas atenderam ao objetivo deste texto e não foi necessário retomar a entrevista para complementar informações. Após a transcrição para a língua escrita, o participante solicitou revisão própria e inseriu informações que não constavam na entrevista por vídeo.

Para o tratamento e a análise dos dados, utilizou-se a análise temática, que consiste em separar o texto transcrito em conteúdo de acordo com os temas identificados (MANZINI, 2020; BARDIN, 2016). Esse tipo de análise é indicado para a classificação de entrevistas semiestruturada e não estruturada. No caso específico deste trabalho, foram identificados cinco temas: 1) a biblioteca da escola bilíngue para surdos; 2) dificuldades na biblioteca no ensino superior; 3) os recursos de Tecnologia Assistiva nas bibliotecas; 4) relacionamento com o bibliotecário e equipe da biblioteca; 5) o que é preciso para incluir o surdo em uma biblioteca.

\section{Resultados e discussão}

O participante deste estudo frequentou uma escola de surdos localizada no interior do estado do Paraná e foi convidado a relatar sua experiência em bibliotecas, durante seu percurso acadêmico.

\section{A biblioteca da escola bilíngue de surdos}

Como esperado, nas escolas bilíngues de surdos, os profissionais são especializados em Educação Especial e proficientes em Libras, por isso, na biblioteca, além do grande número de materiais visuais, dicionários em Libras e vídeos, o participante deste estudo tinha o apoio de uma bibliotecária (embora ele não saiba informar se era bibliotecária por formação ou encarregada da biblioteca) habilitada em Libras. Como ele descreveu:

[...] Na biblioteca eu me sentia calmo e tranquilo, porque eu lia os livros e o que eu não entendia, eu pedia um dicionário de Libras. [...] Se eu tivesse alguma dúvida, era só perguntar para a profissional da biblioteca e ela me ajudava. 
A qualidade do ambiente envolve mais do que aspectos de infraestrutura, mobiliário e tecnologia, envolve também a comunicação. E esse conjunto de fatores é responsável por apresentar um ambiente favorável ao uso e à frequência do usuário na biblioteca. Trata-se de uma situação que se estende as demais deficiências, por isso deve ser incorporada às rotinas bibliotecárias.

\section{Dificuldades no ensino superior}

Segundo o participante, suas dificuldades começaram quando ingressou no ensino superior, durante a primeira graduação na área de exatas. Além do impacto com um ambiente fora dos padrões conhecidos e vivenciados por ele (em uma escola bilíngue para surdos), deparou-se com as especificidades do curso escolhido, pois não contava com o auxílio de um intérprete. Afirmou que sentia dificuldade em localizar os materiais do curso e não encontrava materiais específicos sobre a surdez, o que dificultava a consulta.

[...] a comunicação era bem ruim e não tinha nenhum tipo de acessibilidade. Eu pedia textos e livros aos professores para ler depois. Na biblioteca tem computador, que você insere o nome do livro e precisa encontrar o número nas prateleiras. [...] Eu sofria muito na biblioteca porque estava sempre sozinho, mas consegui me formar.

Posteriormente, ao ingressar na segunda graduação, na área de humanas, houve mais familiaridade com os assuntos estudados e os temas eram mais próximos de sua realidade, pois, por ser um curso de licenciatura, a Libras e a Educação bilíngue, que foram estudadas, eram também vivenciadas, o que trazia algum conforto ao buscar materiais, mesmo que não fossem adaptados para ele.

O fato de estudar algo que lhe oferecia maior familiaridade tornou-se uma motivação para que fosse buscar acolhimento em uma área que relativamente lhe pertencia.

Quando decidiu que tentaria o Mestrado, encontrou dificuldade no momento do ingresso, pois no processo seletivo não tinha disponível um intérprete para acompanhá-lo. Com o auxílio de uma estudante do mesmo programa, que estava em aula e era sinalizante da Libras, conseguiu seguir para as próximas fases e foi aprovado.

Ao conhecer a biblioteca do novo campus, percebeu as mesmas dificuldades que encontrou em suas fases de graduação: dificuldade em localizar materiais específicos para sua condição (surdo), além de não conseguir orientação para localizar materiais que procurava no 
acervo da instituição, ausência de materiais em Libras e a falta de comunicação, o que comprometia seu atendimento, “[...] era muito ruim, desconfortável, desagradável [...]”.

\section{Os recursos de tecnologia assistiva nas bibliotecas}

A respeito dos recursos de Tecnologia Assistiva, o participante percebia que a biblioteca contava com recursos para pessoas cegas, mas não para surdos. “[...] Até hoje eu não encontrei e não uso a TA porque não tem. Eu espero que exista no futuro e que eu possa usar, mas por enquanto, não tem [...]”.

Embora a literatura aponte alguns recursos disponíveis para as bibliotecas, o participante não citou nenhum específico que atenda os surdos. Talvez ele também desconhecesse o que o poderia ser disponibilizado no ambiente, ou que apenas não quisesse explicar melhor sua resposta.

\section{Relacionamento com o bibliotecário e equipe da biblioteca}

O participante relatou que, sem ajuda, fazia buscas na biblioteca, mas poderia contar com o intérprete de Libras desde que marcasse antecipadamente. O intérprete estava sempre ocupado e somente mediava a comunicação em sala de aula. Questionado sobre o relacionamento (ou a ausência dele) com o bibliotecário e a equipe da biblioteca, o participante relatou:

\footnotetext{
Com a profissional da escola regular era muito boa. Ela sempre me ajudava com as dúvidas. Mas nas faculdades, não tinha intérprete e as pessoas nem chegavam perto de mim. Eu acho que eles sentem receito ou medo de chegar perto de uma pessoa surda porque não conseguem se comunicar em Libras. [...] eu percebo o nervosismo das pessoas quando sabem que sou surdo.
}

A respeito de oferecer alguma sugestão para os profissionais locais de como poderiam auxiliá-lo, o participante disse que nunca fez sugestão alguma, não foi solicitado e não se ofereceu para tal, mas não descarta a possibilidade de contribuir para que outros estudantes, como ele (surdos, com deficiências e/ou limitações), não passem por tantas dificuldades.

No próximo semestre eu irei sim. Porque eu não penso só em mim. Eu também penso nos outros surdos: como é que eles irão à biblioteca? No futuro, como eles frequentarão a biblioteca? Então, na biblioteca há problemas muito sérios de acessibilidade e de comunicação. Olha, por exemplo: a profissional da biblioteca... a pessoa cega tem ajuda? Tem apoio? Tem? É de se pensar e eu pergunto sobre isso. Outra coisa, se o cego tem Braille, por que o surdo não tem apoio em Libras? Por que o surdo não? Eu não sei! É algo para se pensar e observar. 
Documentos oficiais recomendam a escuta ao usuário, conforme já citado neste texto, portanto cabe à gestão e à equipe da biblioteca estabelecer um canal de comunicação e incorporar a prática em suas rotinas e ações. É preciso lembrar que não são iguais em suas necessidades, portanto, equipamentos e recursos de Tecnologia Assistiva precisam ser direcionados e atender às diversas deficiências.

\section{O que é preciso para incluir o surdo em uma biblioteca?}

Para o participante, “[...] a primeira coisa que o profissional da biblioteca precisa é conhecer a Libras, e a segunda é pensar: como eu posso ajudar?

Segundo ele, “[...] o sentimento do surdo será melhor, o desenvolvimento de seu trabalho será produtivo e poderá evoluir. No Mestrado eu não tenho nada na biblioteca. Nenhuma acessibilidade, nenhum apoio, nenhuma ajuda... e eu vou fazer o quê? “

\section{Considerações finais}

As bibliotecas ainda não estão bem preparadas para atender ao usuário surdo, é o que se comprova diante do relato do estudante entrevistado. Conforme mostra a literatura, existem possibilidades para realizar um atendimento inclusivo, desde que a equipe seja capacitada, o acervo especializado e as adaptações necessárias oferecidas. Mesmo que o estudo tenha uma amostra considerada pequena, não pode ser desconsiderado devido à importância do relato dentro do contexto apresentado.

Vale ressaltar que as amostras de estudos que envolvem pessoas com deficiência, em geral são menores, por inúmeras questões, como a exposição da condição do indivíduo, a disponibilidade para contribuir com os estudos ou poucos envolvidos na situação em que envolve a proposta de estudo. Por isso, não se tornam inviáveis e sim oportunidades para compreensão e entendimentos.

$\mathrm{O}$ entrevistado demonstrou o quanto a falta de pertencimento em uma biblioteca o constrange e o quanto é "tranquilo" estar em um ambiente onde era compreendido (na escola bilíngue). Não é possível deixar um usuário isolado em seu processo de aprendizado, é preciso 
buscar capacitação e investir nas equipes para que a importância a respeito da inclusão se torne uma responsabilidade de todos.

Estudos sobre o usuário surdo e demais deficiências ainda são reduzidos na Biblioteconomia e mostram a importância de despertar a atenção do bibliotecário e o quanto estes precisam conhecer seus usuários. É preciso que ações sejam realizadas e que atuações sejam repensadas, com a finalidade de mudar posturas e oferecer mais proximidade nos ambientes informacionais.

É notória a importância da Libras no estabelecimento de uma comunicação entre o surdo e ouvinte, porém, não é a única forma de interação que pode ser estabelecida com pessoas surdas. Existem recursos de Tecnologia Assistiva disponíveis que podem ser utilizados e, com isso, os meios ampliados e facilitados na busca pela compreensão durante a interação com outras comunidades.

O fato de o participante desse relato estar inserido em um ambiente universitário pode despertar, entre os estudantes e professores não sinalizadores de Libras, a possibilidade de se encontrar outros meios para manter a inclusão efetiva do estudante surdo, como a comunicação pela escrita, por exemplo, que não é o meio de interação ideal, mas o real, que pode oferecer condições para se evitar a exclusão, o isolamento e o preconceito da sociedade.

Além disso, os registros na literatura e a entrevista com o usuário surdo mostram que as dificuldades encontradas por eles nas bibliotecas podem comprometer o desenvolvimento de pesquisas. Sem materiais que lhe favoreçam a compreensão de disciplinas ou demais assuntos tratados na academia, como ele poderá desenvolver sua dissertação ou tese, além de alcançar avanços necessários para o seu desenvolvimento intelectual e social?

Os ambientes ainda são insuficientes com a falta de Comunicação Visual na sinalização e na divulgação de produtos e serviços existentes e oferecidos à comunidade local.

A falta de sinalização em Libras, que poderia orientá-lo melhor no uso do ambiente na biblioteca, também é fator de atenção, pois nem sempre o que está escrito é bem compreendido. Por necessitar de informações visuais além da escrita da língua portuguesa, que é considerada uma língua estrangeira (L2) à comunidade surda, sua necessidade informacional se torna secundária. É pela Libras que lhe será proporcionado o conhecimento, sua necessidade primária. 
Materiais especializados em Libras no acervo e os recursos de TA específicos para surdos nem sempre existem na biblioteca, ou, às vezes, não são utilizados e disponibilizados como deveriam.

Os recursos de Tecnologia Assistiva apresentam grandes possibilidades para que as pessoas com deficiência (surdos e/ou com limitações) se tornem autônomas, independentes em suas atividades e atendidos em suas necessidades. A existência de recursos de TA para cegos em uma biblioteca não garante que também sejam úteis para surdos. Se cada deficiência tem suas especificidades, cada pessoa surda também. Dessa forma, é preciso conhecer a necessidade de cada usuário, que indicará a forma de auxiliá-lo.

A ausência da comunicação constitui uma barreira que o bibliotecário e o usuário não conseguiram transpor. A comunicação favorece o atendimento, portanto, seja de forma básica ou fluente, o conhecimento a respeito da Libras é um fator determinante para quem a utiliza, no entanto, não deve ser vista como a única a ser estabelecida, como citado neste texto. Existem outras formas, seja com uso de aplicativos ou quando possível, de forma escrita. Essa necessidade de comunicação não deve se restringir apenas às bibliotecas especializadas, mas estabelecida para todas, pois não há como prever onde estará o usuário com deficiência ou quando ele precisará consultar um bibliotecário.

Conclui-se que um atendimento inclusivo pode estar muito próximo de uma realidade se houver conhecimento a respeito da necessidade do usuário. Não é possível planejar um ambiente acessível sem pensar em quem vai utilizá-lo. E para conhecer o usuário, nada melhor do que ouví-lo, é o que sugerem os documentos oficiais e norteadores de ações em bibliotecas.

A ideia de adaptar, modificar ou adquirir algo mediante a presença do usuário precisa ser abolida. É preciso que os ambientes se tornem inclusivos naturalmente.

As normas técnicas atendem e preveem modificações para auxiliar as pessoas com deficiência (surdas e/ou com limitações), por isso é preciso que as bibliotecas estejam adequadas às necessidades e especificidades de seus usuários.

Como sugerido pela literatura, conhecer e ouvir o usuário pode ser a chave para que as bibliotecas sejam espaços inclusivos, daí a importância desse ambiente para a busca de pesquisas e informações acadêmicas. 


\section{Referências}

AMERICAN LIBRARY ASSOCIATION. People with multiple disabilities: what you need to know. 2017. Disponível em:

http://www.ala.org/asgcla/files/asclaprotools/accessibilitytipsheets/tipsheets/12-

Multiple_Disabili.pdf Acesso em: 15 jul. 2020.

ARAUJO, E.M. et al. Princípios básicos da Língua Brasileira dos Sinais (Libras): uma experiência na biblioteca da EESC/USP. Revista Brasileira de Biblioteconomia e

Documentação, São Paulo, v. 13, n. esp. CBBD, 2017. Disponível em:

https://portal.febab.org.br/anais/article/view/1904 Acesso em: 04 nov.2021.

ASSOCIAÇÃO BRASILEIRA DE NORMAS TECNICAS. NBR15599: acessibilidade: comunicação na prestação de serviços. Rio de Janeiro: ABNT, 2008.

ASSOCIAÇÃO BRASILEIRA DE NORMAS TECNICAS. NBR 9050: acessibilidade a edificações, espaço, mobiliário e equipamentos urbanos. 3.ed. Rio de Janeiro: ABNT, 2015.

BARDIN, L. Análise de conteúdo. São Paulo: edições 70, 2016.

BATISTA, L.; NASCIMENTO, E.H. A deficiência vai à universidade: perspectivas e entraves do processo inclusivo na educação superior brasileira. Educação Unisinos, v.22, n. 2, p. 120-127, abr./jun. 2018. Disponível em:

http://revistas.unisinos.br/index.php/educacao/article/view/edu.2018.222.01/60746204 Acesso em: 04 nov.2021.

BRASIL. Constituição da República Federativa do Brasil: D.O. 5 de outubro de 1988. Disponível em: www.mec.gov.br/legis/default.shtm . Acesso em: 31 jul. 2020.

BRASIL. Lei 9394/96: Lei de diretrizes e bases da Educação Nacional. Brasília: MEC, 1996.

BRASIL. Lei n. 10.436, de 24 de abril de 2002. Dispõe sobre a Língua Brasileira de Sinais Libras e dá outras providências. Diário Oficial da União, Brasília, DF, 25 abr. 2002.

Disponível em: http://www.planalto.gov.br/ccivil_03/leis/2002/110436.htm . Acesso em: 03 jul. 2020.

BRASIL. Decreto no 5626 de 22 de dezembro de 2005. Brasília: Presidência da República, Casa Civil, Subchefia para Assuntos Jurídicos. Disponível em:

http://www.planalto.gov.br/ccivil_03/ato2004-2006/2005/decreto/d5626.htm . Acesso em: 27 jul. 2020.

BRASIL. Ministério da Educação. Política Nacional de Educação Especial na Perspectiva da Educação Inclusiva. Brasília, DF: MEC, 2008.

BRASIL. Planalto. Lei n. 13146 de 06 de julho de 2015: institui a Lei brasileira de inclusão da pessoa com deficiência (Estatuto da pessoa com deficiência). Disponível em: http://www.planalto.gov.br/ccivil_03/_ato2015-2018/2015/lei/113146.htm Acesso em: 22 jul. 2020. 
CAPURRO, R. Epistemologia e ciência da informação. In: ENCONTRO NACIONAL DE PESQUISA EM CIÊNCIA DA INFORMAÇÃO, 5., Belo Horizonte, 2003. Anais... Belo Horizonte: ECI-UFMG, 2003. Disponível em: http://www.capurro.de/enancib_p.htm Acesso em: 01 dez. 2020.

DIAS, M. R.; BOM, G. Um olhar ao estudante com surdez da Universidade Federal do Rio Grande do Norte: análise sobre a acessibilidade à informação na Biblioteca Central Zila Mamede. BiblioCanto, Natal, v. 5, n. 1, p. 83-104, 2019. Disponível em: https://periodicos.ufrn.br/bibliocanto/article/view/18864 Acesso em: 10 jul. 2020.

DUARTE, A.B. S. Mediação da informação e estudos de usuários: interrelações. InCID: R. Ci. Inf. e Doc., Ribeirão Preto, v. 3, n. 1, p. 70-86, jan./jun. 2012. Disponível em: http://www.revistas.usp.br/incid/article/download/42370/46041/Acesso em: 20 jul. 2020.

FERREIRA, R. R.; CHAGAS, K. R. O bibliotecário como mediador no processo de inclusão do surdo em bibliotecas universitárias. Revista Bibliomar, São Luís, v. 15, n. 1/2, jan./dez, 2016. Disponível em:

http://www.periodicoseletronicos.ufma.br/index.php/bibliomar/article/download/6623/4274 Acesso em: 10 jul. 2020.

FORTALECIMENTO de bibliotecas acessíveis e inclusivas: manual orientador. São Paulo: Mais Diferenças, 2016. Disponível em: http://www.maisdiferencas.org.br/site/noticias/?id=245. Acesso em: $01 \mathrm{dez} .2020$.

GOLDFELD, M. A criança surda: linguagem e cognição numa perspectiva sóciointeracionista. São Paulo: Plexus, 1997.

HERINGER, R. Democratização da educação superior no Brasil: das metas de inclusão ao sucesso acadêmico. Rev. bras. orientac. prof, Florianópolis, v. 19, n. 1, p. 7-17, jun. 2018. Disponível em: http://pepsic.bvsalud.org/scielo.php?script=sci_arttext\&pid=S1679-

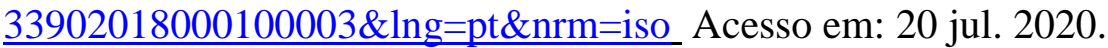

HONORA, M.; FRIZANCO, M. L. Esclarecendo as deficiências: aspectos teóricos e práticos para contribuir para uma sociedade inclusiva. São Paulo: Ciranda Cultural, 2015.

INSTITUTO BRASILEIRO DE GEOGRAFIA E ESTATISTICA (IBGE). Censo demográfico 2010: características gerais da população, religião e pessoas com deficiência. Rio de Janeiro, 2010.

INTERNATIONAL FEDERATION OF LIBRARY ASSOCIATIONS AND INSTITUTTIONS (IFLA). Manifesto IFLA para biblioteca escolar. Tradução: Neusa Dias de Macedo. 1999. Disponível em: http://www.ifla.org/VII/s11/pubs/portuguese-brazil.pdf . Acesso em: 04 nov.2021.

ISHIMOTO, A. T.; ROMÃO, L. M. S. O silêncio dos ouvintes: o bibliotecário em relação ao leitor surdo. Biblionline, João Pessoa, v. 11, n. 2, p. 31-42, 2015. Disponível em: https://periodicos.ufpb.br/ojs2/index.php/biblio/article/view/26719/15187 . Acesso em: 21 jul.2020. 
LACERDA, C. B. F.; NAKAMURA, H.; LIMA, M. C. (Org.). Fonoaudiologia: surdez e abordagem bilíngue. São Paulo: Plexus, 2000. p. 21-41.

MANZINI, E. J. Análise de entrevista. Marília: Abpee, 2020.

MANZINI, E. J.; OLIVEIRA, J. P.; GERMANO, G. D. (Org.). Política de e para educação especial. Marilia: ABPEE, 2018.

MIGLIOLI, S.; SANTOS, G. A. Acessibilidade e serviços inclusivos para minorias sociais: a biblioteca do Instituto Nacional de Educação de Surdos. Revista ACB: Biblioteconomia em Santa Catarina, Florianópolis, v. 22, n. 1, p. 136-149, dez./mar., 2017. Disponível em: https://revista.acbsc.org.br/racb/article/view/1278 Acesso em: 15 jul. 2020.

MIRANDA, S. N. Acessibilidade ao usuário surdo e com deficiência auditiva em bibliotecas universitárias: o caso da UNIRIO. 2015. Dissertação (Mestrado Profissional em Biblioteconomia) - Universidade Federal do Estado do Rio de Janeiro, 2015. Disponível em: http://www.repositorio-bc.unirio.br:8080/xmlui/handle/unirio/11904 Acesso em: 10 jul. 2020.

MIRANDA, S. N. Comunicação acessível aos usuários surdos e com deficiência auditiva em bibliotecas: uma análise das normas brasileiras. Revista Brasileira de Biblioteconomia e Documentação, v. 13, 2017. Disponível em: https://rbbd.febab.org.br/rbbd/article/view/847 Acesso em: 5 jul.2020

MIRANDA, S. N.; COSTA, M. V. S. B.; SILVA, M. M. O usuário surdo e a acessibilidade no sistema de bibliotecas da UNIRIO. Revista Brasileira de Biblioteconomia e Documentação, São Paulo, v. 13, n. 2017, p. 2008-2019, 2019. Disponível em: https://rbbd.febab.org.br/rbbd/article/view/971 Acesso em: 04 nov.2021.

PERLIN, G. T. T. Identidades surdas. In: SKLIAR, C. (org). A surdez. Porto Alegre: Mediação, 2013. p.51-73.

SANTOS, M. P.; DINIZ, C. N.; RANGNI, R. A. Pessoas surdocegas em bibliotecas: discussões iniciais. Revista Brasileira de Biblioteconomia e Documentação, v. 13, p. 2051 2064, 2017. Disponível em: https://rbbd.febab.org.br/rbbd/article/view/1002 Acesso em: 04 nov.2021.

SILVA, J. L. C. Necessidades de informação e satisfação do usuário: algumas considerações no âmbito dos usuários da Informação. InCID: R. Ci. Inf. e Doc., Ribeirão Preto, v. 3, n. 2, p. 102-123, jul./dez. 2012. Disponível em: http://www.revistas.usp.br/incid/article/view/486566 Acesso em: 20 jul. 2020.

SILVA, A. G. Acessibilidade na Universidade do Estado do Pará - UEPA: um estudo nos campi da capital (Belém). In: MARTINS, L. A. R. et al. Educação \& Diversidade: saberes e experiências. João Pessoa: Editora Universitária UFPB, 2010. p. 179 - 192.

SKLIAR, C. Uma análise preliminar das variáveis que intervêm no Projeto de Educação Bilíngue para os Surdos. Espaço Informativo Técnico Científico do INES. Rio de Janeiro, v. 6, p. 49-57, 1997.

SKLIAR, C. (Org.) Atualidade da educação bilíngue para surdos. Porto Alegre: Mediação, 1999. v. 1-2. 
STROBEL, K. As imagens do outro sobre a cultura surda. Florianópolis: UFSC, 2008.

VIEIRA, L. C. B. Biblioteca inclusiva: repensando políticas de acesso e inclusão para deficientes auditivos na Universidade Federal do Maranhão. Biblionline, João Pessoa, v. 10, n. 1, p. 82-101, 2014. Disponível em:

https://periodicos.ufpb.br/ojs/index.php/biblio/article/view/17882 Acesso em: 20 jul. 2020.

WELLICHAN, D. S. P.; SOUZA, C. S. A inclusão na prática: estudantes com deficiência no Ensino Superior. Revista on line de Política e Gestão Educacional, Araraquara, v. 21, n. 1, p. 146-166, 2017. Disponível em:

https://periodicos.fclar.unesp.br/rpge/article/view/9786/6596 Acesso em: 20 jul. 2020.

Artigo submetido em: 12 jan. 2021

Artigo aceito em: 29 jun. 2021 